http://jmscr.igmpublication.org/home/ ISSN (e)-2347-176x ISSN (p) 2455-0450 crossref DOI: https://dx.doi.org/10.18535/jmscr/v8i7.03

\author{
Journal Of Medical Science And Clinical Research \\ IGM Publication \\ An official Publication of IGM Publication
}

\title{
Anthropometric study of hip joint characteristics in the Kashmir valley with Computed Tomography
}

\author{
Authors \\ Muhammad bin Abdul Hamid ${ }^{1}$, Nadia Rashid ${ }^{2}$, Omar Khursheed $^{3}$ \\ ${ }^{1}$ Junior Resident, Deptt of Orthopaedic Surgery, Government Medical College, Srinagar, India \\ ${ }^{2}$ M.B.B.S. Government Medical College, Srinagar, India \\ ${ }^{3}$ Senior Resident, Deptt of Orthopaedic Surgery, Government Medical College, Srinagar, India
}

\begin{abstract}
Background: An understanding of anthropometric measurements of the hip joint, in any given population has important clinical and logistical implications in the orthopaedic setting. A study of this nature, utilizing computed tomography, has not been conducted on the Kashmiri population, and this study aims to bridge that gap.

Materials and Methods: The study evaluated 80 individuals, with otherwise normal hips to be included in the study. All of these patients had CT of the abdomen/pelvis done for unrelated reasons, and anthropometric data for the hip was obtained from examining these sections. Parameters studied were the $C E$ angle. acetabular angle, acetabular version, neck shaft angle, and the vertical diameter of the femoral head.

Results: The following were the mean values obtained: Acetabular angle: $39.2^{\circ}$, acetabular version: $18.8^{\circ}$, CE angle (of Wiberg): $33.9^{\circ}$, neck-shaft angle: $139.5^{\circ}$, vertical femoral head height: $45.3 \mathrm{~mm}$

Conclusion: The hip joint parameters measured in our study were comparable to other studies conducted on Indian, as well as western population. The neck shaft angle in our study was higher than that studied in the western population.
\end{abstract}

\section{Introduction}

An extensive knowledge of the hip joint anatomy is essential to understand its biomechanics. Although mean anthropometric values give an idea of what to expect, it should be known how far do the normal values deviate, and where pathological values can be expected ${ }^{(1)}$.

Computed tomography enables us to accurately map and measure the anthropometric values of the hip joint.

Different researchers have proposed that there are differences in parameters of bone among different races, and they have tried to figure out the relationship of these variations to an increase in the incidence of hip osteoarthritis, neck of femur fractures and slipped capital femoral epiphysis ${ }^{(2)}$. Wiberg, in his early reports suggested the relationship of development of osteoarthritis to the presence of acetabular dysplasia ${ }^{(3)}$

The purpose of this study is to determine normal hip anthropometric parameters of the Kashmir population, and compare it with the data available worldwide.

\section{Materials and Methods}

80 individuals with normal hips, and those falling between age groups of 20-70 years were included in the study. These patients had CT of the pelvis 
done for unrelated reasons, and hip measurements were calculated from those CT scans, after taking informed written consent from each individual.

Almost all of the population in this region falls under the Caucasoid group. This group is characterized by the presence of a long head, narrow face, high forehead, long nose, and generally tall in stature.

Excluded were individuals who were skeletally immature, and persons not originally belonging to this region.

The height of each individual was measured.

All the CT scans were taken maintaining a fixed and specified technical configuration while taking the cuts. CT scans were done in the supine position, with hips and knees fully extended. Feet were stabilized while taking cuts.

All measurements were taken on CT scan.

Acetabular anteversion was recorded on an axial cut that passed through the enter of the hip joint. This corresponds to the anteversion described by
Murray et $\mathrm{al}^{(4)}$. Femoral anteversion was not recorded, as femoral condyles were not included in most of the CT scans.

The following is the definition of the parameters used:

1. Acetabular angle (of Sharp): Angle between horizontal line drawn through the tip of pelvic tear drop, and a line from the tip of tear drop to the anterior edge of acetabulum.

2. CE angle of Wiberg: Angle between a line drawn vertically through the center of femoral head and a second line drawn from the center of femoral head to anterior edge of acetabulum.

3. Neck-shaft angle: Angle subtended between the axes of the femoral neck, and shaft.

4. Acetabular version: Angle between the perpendicular drawn to the line connecting posterior margins of ischial tuberosities, and a line connecting the posterior and anterior margins of acetabulum (Figure 1.3).

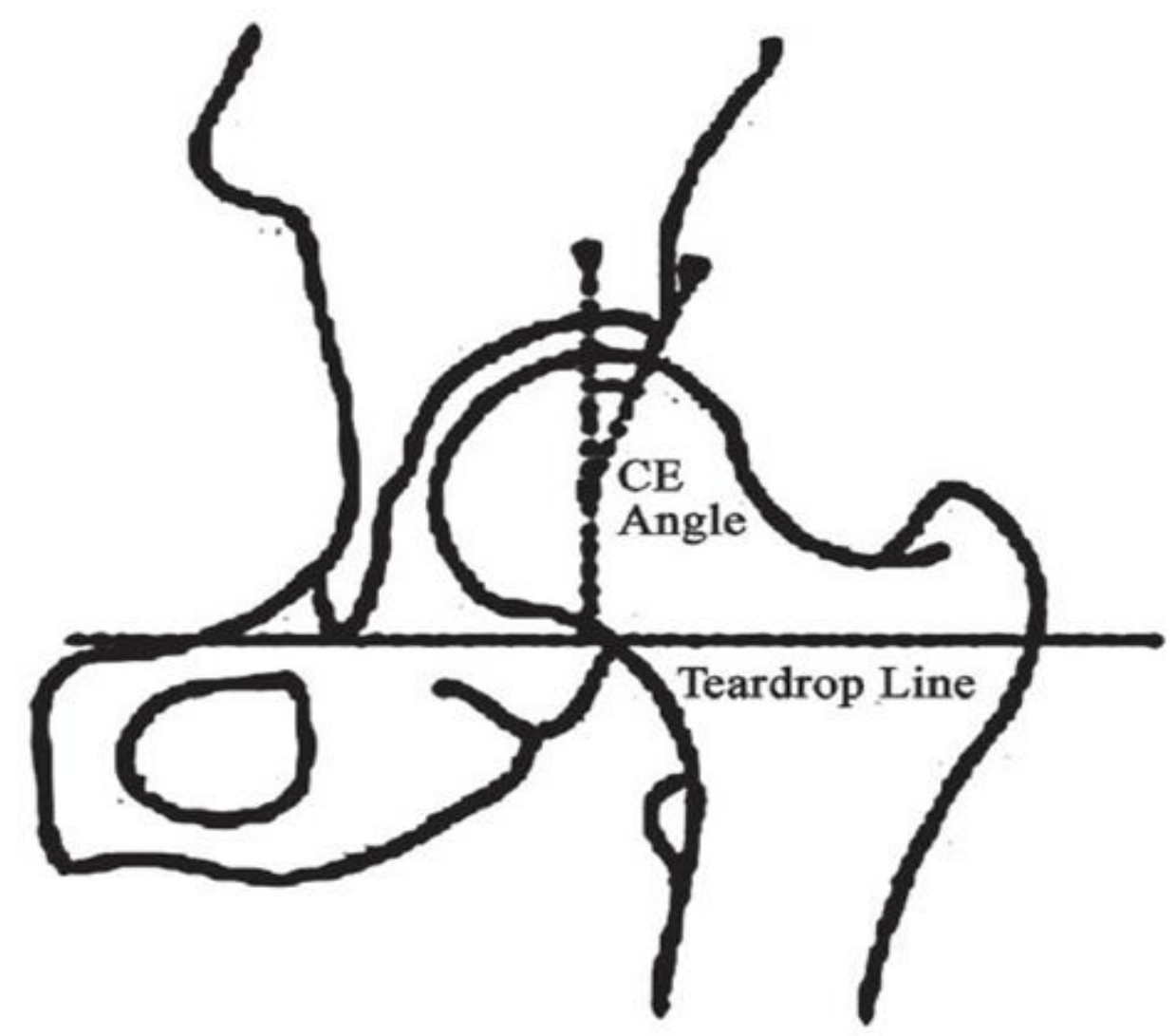

Figure 1.1: Line diagram depicting the CE angle (of Wiberg) (5) 


\section{JMSCR Vol||08||Issue||07||Page 09-13||July}

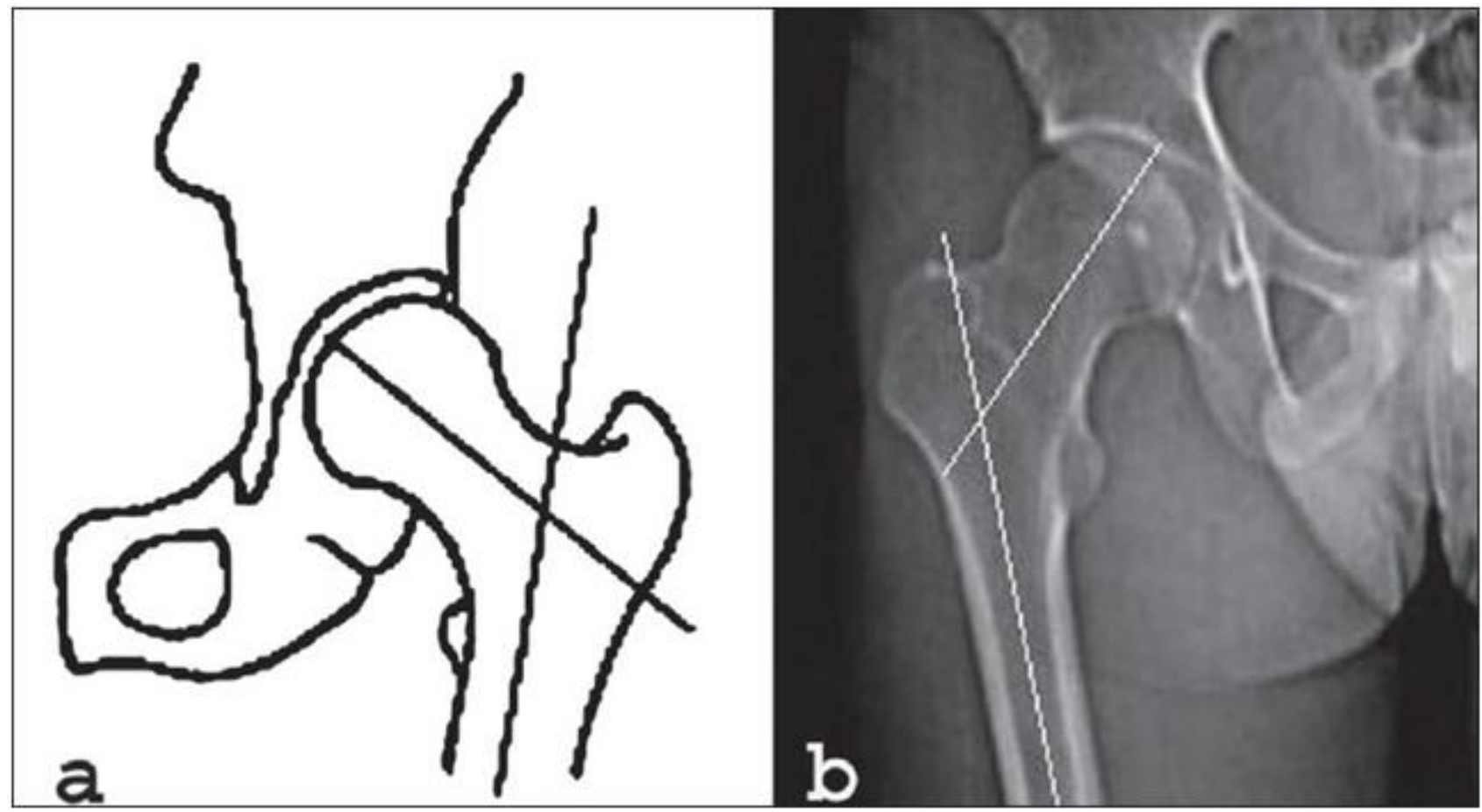

Figure 1.2: Calculation of the neck shaft angle. (5)

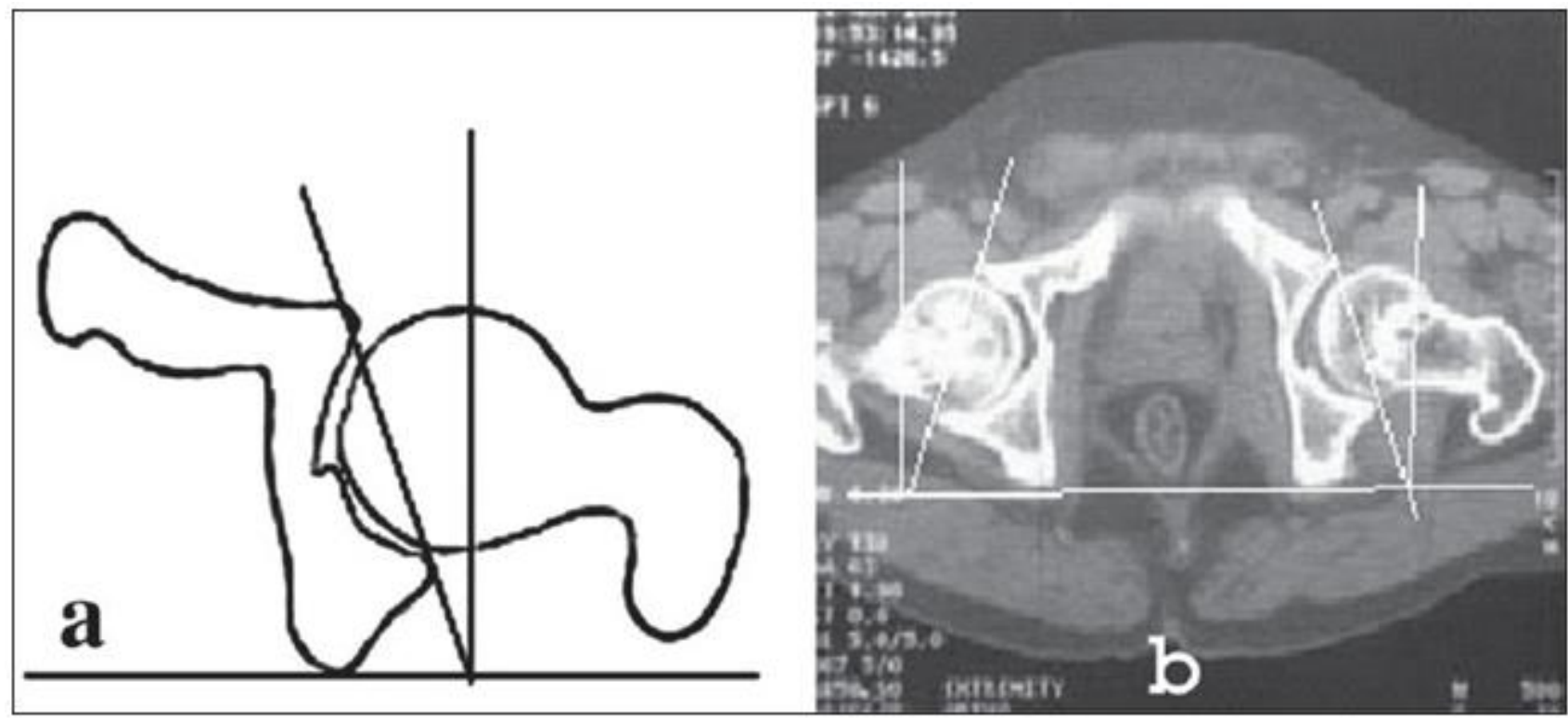

Figure 1.3: Measurement of acetabular version (see text) (5)

\section{Results}

There were 49 males, and 31 females included in our study. The mean height of the male patients was $167.2 \mathrm{~cm}$ (range $156.8-178.6 \mathrm{~cm}$ ), and of the female patients was $156.8 \mathrm{~cm}$ (range 146.4$167.8 \mathrm{~cm})$.

The mean acetabular angle was $39^{\circ}$ in males, and $39.4^{\circ}$ in females, whereas the CE angle (of Wiberg) was $33.1^{\circ}$ and $34.7^{\circ}$ respectively. The acetabular version was $19^{\circ}$ in males and $18.6^{\circ}$ in females. The mean neck shaft angle measured was $139^{\circ}$, and vertical diameter of femoral head was $45.3 \mathrm{~mm}$

The results are specified in the table shown below. 
Table 1 Comparison between sexes

\begin{tabular}{|l|c|c|c|c|c|c|}
\hline $\mathbf{n}$ & & $\begin{array}{c}\text { Acetabular } \\
\text { angle (deg.) }\end{array}$ & $\begin{array}{c}\text { CE angle } \\
\text { (deg.) }\end{array}$ & $\begin{array}{c}\text { Neck shaft } \\
\text { angle (deg.) }\end{array}$ & $\begin{array}{c}\text { Acetabular version } \\
\text { (deg.) }\end{array}$ & $\begin{array}{c}\text { Vertical Head } \\
\text { diameter (mm) }\end{array}$ \\
\hline 49 & Male & & & & & 19 \\
\hline & Mean & 39 & 33.1 & 141 & 5.0 & 46.4 \\
\hline & SD & 2.4 & 10.5 & 5.2 & & 2.4 \\
\hline 31 & Female & & & & 18.6 & 44.2 \\
\hline & Mean & 39.4 & 34.7 & 138 & 5.6 & 2.6 \\
\hline
\end{tabular}

SD - Standard deviation, deg. - degree, cm - centimeter, mm - millimeter;

\section{Discussion}

Variations in hip anthropometric parameters have been found in different regions worldwide, and racial characteristics, for the most part, determine the general anthropometric profile of a population, as was evident in a study by Saikia et $\mathrm{al}^{(5)}$

Earlier studies documenting these parameters using plain radiographs have given us an idea of the range of measurements in the Caucasoid population $^{(6)}$. We have used CT scans to make a more accurate quantitative analysis of the parameters of the adult hip joint in our study.

The CE angle was described first by Wiberg ${ }^{(3)}$ in 1939. Values greater than $25^{\circ}$ are considered normal, whereas less than $20^{\circ}$ dysplastic. In an adult Indian population studied by Mandal et $\mathrm{al}^{(7)}$ concluded that in $83 \%$ of the studied population, the $\mathrm{CE}$ angle was between $28^{\circ}$, ad $42^{\circ}$. None of the hips had a CE angle of less than $20^{\circ}$, and a similar pattern was seen when compared with Caucasians, and Africans. Osteoarthritis of the hip, being rare in Indians and Africans, while being more common in white Caucasians despite having similar anthropometric characteristics, suggests that acetabular dysplasia may not have a significant role in the development of osteoarthritis. In our series, the mean CE angle was $33.9^{\circ}$.

The acetabular angle was first described by Sharp et $\mathrm{al}^{(8)}$ in 1961. It has been employed to diagnose the presence of dysplasia. Values $>43^{\circ}$ are considered abnormal. Nakamura et $\mathrm{al}^{(9)}$, in their study reported a mean measurement of $38^{\circ}$, and standard deviation of $3.6^{\circ}$ in a cohort of Japanese subjects. In our study, we found the mean acetabular angle to be $39.2^{\circ}$, with a mean SD of $2.65^{\circ}$.

The femoral neck-shaft angle has shown considerable variation, and a wide standard deviation among different populations. In their research published in 1980, Hoaglund and Low ${ }^{(10)}$ concluded that the average neck shaft angle in adults was $135^{\circ}$. Lequesne et $\mathrm{al}^{(2)}$, in their study reported a mean value of $132.8^{\circ}$. In the present study, the average neck shaft angle was $139.5^{\circ}$, with a mean SD of $5.4^{\circ}$.

Acetabular version, was studied in the research by Reikeras et $\mathrm{al}^{(11)}$ in 1983 , and they compared the measurements among normal, and osteoarthritic hips. The normal mean and SD were $17^{\circ}$ and $6^{\circ}$ respectively. In the present study, our calculated mean was $18.8^{\circ}$.

It has been suggested that the vertical diameter of the femoral head is larger in taller individuals ${ }^{(12,13)}$. Nigerian femora, have been reported to have a mean femoral head diameter of $54.23 \mathrm{~mm}$ in males, and $54.08 \mathrm{~mm}$ in females ${ }^{(12)}$. In an Indian cadaveric study, Chauhan et al, reported a mean vertical diameter of femoral head in males and females to be $45.64 \mathrm{~mm}$ and $44.27 \mathrm{~mm}$ respectively. Our study was comparable to the Caucasoid Indian population; we reported a mean diameter of $46.4 \mathrm{~mm}$ and $44.2 \mathrm{~mm}$, in men and women respectively.

The Indian subcontinent is an amalgamation of a vast collection of different morphological, genetic, and cultural characteristics. There is considerable influence of large-scale migration from Central, and South-east Asia into the mainland in historical times. 
Knowledge of the anatomical parameters of the hip joint is essential for understanding pathology, and for preparation before surgery. Knowledge of average dimensions for a particular population would help prioritize proportionate sizing of components, and prostheses that are to be made available. The measurements in this study are both accurate and precise, but to form a broader consensus regarding the validity of data, a larger study with a bigger cohort of participants is needed.

\section{Bibliography}

1. Tönnis D. Normal values of the hip joint for the evaluation of X-rays in children and adults. Clin Orthop. 1976 Sep; (119): 39-47.

2. Lequesne M, Malghem J, Dion E. The normal hip joint space: variations in width, shape, and architecture on 223 pelvic radiographs. Ann Rheum Dis. 2004 Sep; 63(9):1145-51.

3. WIBERG G. Studies on dysplastic acetabula and congenital subluxation of the hip joint. Acta Chir Scand [Internet]. 1939 [cited 2020 Jun 16]; 83(58). Available from: https://ci.nii.ac.jp/naid/10010933620/

4. Murray DW. The definition and measurement of acetabular orientation. $\mathrm{J}$ Bone Joint Surg Br. 1993 Mar;75(2):22832.

5. Saikia K, Bhuyan S, Rongphar R. Anthropometric study of the hip joint in Northeastern region population with computed tomography scan. Indian J Orthop. 2008;42(3):260-6.

6. Khan Dr JM, Banday Dr MI, Muzaffar Dr J. A study of measurement of acetabular diameter radiologically in northern Indian population of Jammu region. Int $\mathbf{J}$ Orthop Sci. 2018 Jul 1;4(3.1):78-81.
7. Mandal S, Bhan S. The centre-edge angle of Wiberg in the adult Indian population. $\mathbf{J}$ Bone Joint Surg Br. 1996 Mar;78(2):320-1.

8. Sharp IK. Acetabular dysplasia. J Bone Joint Surg Br. 1961 May 1;43-B(2):26872.

9. Nakamura $S$, Ninomiya $S$, Nakamura $T$. Primary osteoarthritis of the hip joint in Japan. Clin Orthop. 1989 Apr;(241):190-6.

10. Hoaglund FT, Low WD. Anatomy of the femoral neck and head, with comparative data from Caucasians and Hong Kong Chinese. Clin Orthop. 1980 Oct;(152):10 6.

11. Reikerås O, Bjerkreim I, Kolbenstvedt A. Anteversion of the acetabulum and femoral neck in normals and in patients with osteoarthritis of the hip. Acta Orthop Scand. 1983 Feb;54(1):18-23.

12. Asala SA, Mbajiorgu FE, Papandro BA. A comparative study of femoral head diameters and sex differentiation in Nigerians. Acta Anat (Basel). 1998;162 (4):232-7.

13. Chauhan R, Dhaon B. Anatomical Parameters Of North Indian Hip Joints Cadaveric Study. 2002; 